$\begin{array}{r}\text { Volume and Issues Obtainable at Center for Sustainability Research and Consultancy } \\ \text { Journal of Business and Social Review in Emerging Economies } \\ \text { ISSN: 2519-089X (E): 2519-0326 } \\ \text { Volume 6: No. 4, December 2020 } \\ \text { JSRᄃ } \\ \text { Journal homepage: www.publishing.globalcsrc.org/jbsee } \\ \hline\end{array}$

\title{
Implicit Change Leadership, Affective Commitment to Change, and the Mediating Role of Organizational Trust
}

\author{
${ }^{1}$ Sarfraz Ahmed Dakhan, ${ }^{2}$ Sheraz Rajput, ${ }^{3}$ Tariq Aziz, ${ }^{4}$ Khalil Ahmed Channa \\ 1,2,3,4 Department of Business Administration, Sukkur IBA University, Sukkur, Pakistan, \\ sarfraz@iba-suk.edu.pk
}

\begin{tabular}{l}
\hline ARTICLE DETAILS \\
\hline History \\
Revised format: November \\
2020 \\
Available Online: December \\
2020 \\
\hline Keywords change leadership, \\
Implicit cht, \\
Organizational to \\
Affective commitment to \\
change
\end{tabular}

JEL Classification

M10, M14

\begin{abstract}
This paper aims to know the implicit change leadership schemas, the commitment of the employees towards change, and their relationship with the trust culture of academic institutions. Quantitative approach with surveys of 300 employees of academic institutions has been used in this study. SPSS software has been used to examine the relationship between variables and constructs. Findings reveal that organizational trust has a mediating effect on implicit change leadership and affective commitment to change. Moreover, a positive relationship was found between trust culture and change leadership and change leadership with a commitment to change. Furthermore, the results suggest that change leaders must take into account the trusting culture perspective of the organization to motivate the employees to make them accept change.
\end{abstract}

(C) 2020 Center for Sustainability Research and Consultancy Pakistan under a Creative Commons Attribution-NonCommercial-ShareAlike 4.0

Corresponding author's email address: sarfraz@iba-suk.edu.pk

Recommended citation: Dakhan, S. A., Rajput, S., Aziz, T. \& Channa, K. A. (2020). Implicit Change Leadership, Affective Commitment to Change, and the Mediating Role of Organizational Trust. Journal of Business and Social Review in Emerging Economies, 6(4), 1581-1593

\section{Introduction}

Today's era is the most competing if we compare it with the past. With the latest innovations and technologies, and the increased global competition, organizations have to move towards the latest trends, be innovative to sustain, and to adapt the change (Regiana M.hechanova. Raquel Cementina-Olpoc, 2012).

The fast pace changing environment has also pushed academic institutions towards being more receptive to change, and to be flexible enough to cope with the diverse global business models, policies, cultures, and operational structures. This study will be based on analyzing academic institutions. The thing which needs focus here is that this change is not easy to adapt, it requires efforts, management support, employees' acceptance and most importantly, change leaders and leadership plays a very important role here. Organizations have always found this challenging to deal with change. It is very hard for employees to accept it because it is a matter of moving out of their comfort zones and try to fit into something very new (Lorenzoni, Nicholson, and Whitmarsh, 2007). However, with the help of good leadership culture of change can be developed because leaders are the ones who change the values, 
behaviours, attitude of the employees with their abilities (Ganta, and Manukonda, 2014).

Without a change leader, the prevailing culture of an organization and commitment of the follower engaged in the change process, it is often not possible to execute, maintain and control the change, no matter what actions are required (Metre, 2009). These leaders aim to be change agent, because they identify the change, create a vision and implement a proper strategy (Drucker, 1999; Gilley, 2005; Howkins, 2001). Moreover, the employee's emotional responses to change can be key indicators of how the change will be accepted in an organization. A study by Griffith cooper has argued that change agents may curb the resistance by creating a sense of collaboration between them for a more united action to construct change through their personality characteristics (Griffith-Cooper and King, 2007). Furthermore, these change agents are supposed to be effective communicators, so that there should be high interaction with the employees and more engagement in the change process. They should also have self-motivation, a clear vision, problem-solving skills, ability to provide accurate information, to communicate and negotiate well, and to rapidly take action where necessary (Luscher and Lewis, 2008).

Apart from the leadership, those employees who are emotionally attached with the organization, and feel that their organizations' problems are their own, they show more commitment, are likely to show a positive attitude to organizational change.

Emphasize has been put on in this paper on affective commitment to change since it positively influences the success of change (Cunningham, 2006; Michaelis et al. 2010) and can be likely to be influenced by implicit leadership theory "ILT" (Hechanova, Caringal-Go and Magsaysay (2018). This theory exhibits that subordinates have do have some dispositions for their leaders, the more their schemas match the actual traits of the leaders, the more that leader is perceived as effective (Epitropaki and Martin, 2005). According to this theory, leaders have five dimensions to be an ideal change leader, which this study will examine in the context of academic institutions. These are strategic or technical competence, character, social, execution, and resilience competence at last. (Magsaysay and Hechanova, 2017).

Accepting the change is also influenced by trust culture in the organization where employees have faith in each other's intentions, abilities, behaviours, decisions towards the organizational interest rather than the individual interest and have good trustworthy relationships among them. However, leaders also play a pivotal role when it comes to forming a positive culture in the organization where the trustworthy relationship is made among the employees (Ionescu, 2014). A good leader guides the employee through his interpersonal skills about how to maintain a positive work environment which helps employees to embrace change more rapidly. Further research has also demonstrated the more the trust in leaders' employees have, the more they feel that they are obliged to accept the change (Reinke, 2003)

In this study, we will explore whether there exists to be a positive relationship between implicit change leadership and affective commitment to change. Secondly, we will see how implicit change leadership has an influence on trust culture. We will see the mediating effect of trust culture between change leadership and commitment to change. Lastly, we will see the difference between the actual traits of change leaders and the perceived schemas of the subordinates based on implicit leadership theory (ILT) in academic institutions.

\section{Literature Review}

\subsection{Implicit Change Leadership}

Leadership is an important part of an organization to embrace change and face the challenges of rapid growth in technologies and the economic environment (Cabeza Erikson, Edwards, and Van Brabant, 2008). Leadership is considered to be a special ability through which perceptions, values, attitude and 
beliefs of subordinates can be changed (Ganta, and Manukonda). Change leaders have been emphasized in creating a vision for the future, where employees are motivated and encouraged to accept change. (Bass, 1985; Den Hartog, Van Muijen \& Koopman, 1997; Yammarino \& Bass, 1990). Change leadership has thus been an important factor in the change management process.

\subsection{Why is it Important?}

Research suggests that change is unavoidable and that it is increasing day by day. It's a critical factor which leads to organizational victory (Drucker, 1999; Ford \& Gioia, 2000; Fried-man, 2005; Johansson, 2004; Kuhn, 1970). It can also be seen as the variable which serves ways to gain an edge in the market. (Florida, 2005; Friedman, 2005; Howkins, 2001). Findings reveal that organizations can get a competitive advantage when they adapt transformational and continuous change (Cohen, 1999). Researchers refer to the continuous change which is frequently recurring, emergent, and which never ends (Quinn, 2004; Weick \& Sutcliffe, 2001). Transformational change on the other side refers to the fundamental shift from the current model (Kuhn, 1970). In either case, the researcher agrees that change in the organization is increasing. Change programs where improve organizational performance often disrupts the employee's routines because they have to perform completely new tasks for which they have little knowledge, learn different skills, and adjust with the new people and environment which is why this is the basic source of unwillingness in employees to adapt the change (Chreim, 2006). Any programs in relation to change therefore could result in stress if employees find it difficult to face (Andrews et al., 2008).

For a change, leaders are the building blocks of readiness in the employees in an organization, where adapting change is not readily accepted. Leadership is now as per new paradigm seen from follower's perspective. ILT has assumption every individual has mental predispositions about an ideal leader. (Eden and Leviatan, 1975). Follower uses their cognitive schemas to decide upon the effectiveness and ineffectiveness of leaders (Offermann et al., 1994; Phillips and Lord, 1981). ILT defines that employees perform a matching process between their leader and ILT and if there exits deficiency that reduces the impression of the leader. Reversely, more the congruence between ILT of employee and actual leader, the leader is going to be considered as effective (Epitropaki and Martin, 2005; Schyns et al., 2011).

Leadership schemas in one culture may vary from other culture based on varying expectations and settings in cultures. (Popper and Druyan, 2001). The study with reference to ILT across Asia has shown a different list than the list of other countries. Research by (Ling et al. (2000) exhibited Chinese employees had four patterns to define their leaders: interpersonal competence, goal efficiency, versatility and personal mortality. There has been much research conducted on ILT in the context of different cultures. In a research conducted by (Offermann et al. (1994) started with 160 characteristics thought of as leader characteristics, eventually they revealed eight dimensions defining ideal leaders: strength, tyranny, devotion, attractiveness, charisma, intelligence a counter-prototype trait and sensitivity.

\subsection{What Variables have been Studied through ICL}

A recent study conducted by (Magsaysay and Hechanova, (2017) found out that an ideal leader has five competencies: character, technical and strategic, resilience, execution, and social competencies. Leadership expectation gap occurs when there exists a substantial difference between ILT and actual leader. As per the research conducted by Saltz (2004), stated that follower is to be satisfied with the leader once Leader exhibits the behaviour consistent with follower schema.

\subsection{Relationship between Affective Commitment(AC) to Change}

\subsubsection{ICL}

\subsubsection{AC to Change}

AC to change in this study means the (intentions to bolster for the change having perceived all the benefits resulting from the change). For any change initiative of an organization to succeed it must be 
supported and accepted by its employees (Armenakis and Harris, 2009; Fedor et al., 2006; Smollan, 2006). Commitment to change has an influence on the behaviour and intentions to support change (Herscovitch and Meyer, 2002; Fedor et al., 2006).

\subsubsection{Why is it Important}

A research conducted by Herscovitch and Meyer (2002) showed special interest in investigating the idea of commitment to change which is considered to be the mindset that makes employees pursue the course of actions direly needed for effective implementation of change and formulated the three dimensions of commitment to change (normative, continuance and affective) given the original framework of organizational commitment (Herscovitch and Meyer, 2002). Emphasis on the affective commitment to change since it positively impacts the success of change (Cunningham, 2006; Michaelis et al. 2010) and it is to be positively impacted by ILT (Hechanova, Caringal-Go and Magsaysay (2018).

Moreover, researchers have found a positive relationship between effective leadership and commitment to change. Visionary leaders make employees understand the fair intentions from management side (Harvey et al., 2003). Employees feel committed towards the change and more readily accept the change initiative once they believe that the organization is going to get benefit out of it, and since they deem that the intentions of organizations are worthwhile (Byrne et al., 2005). Furthermore, they also believe that organization is respecting them and is protecting their interests (Korsgaard et al., 2002). By doing so followers tend to perceive the positive outcome of the change and show more commitment towards the change initiative. Consequently, employees show more commitment during a change when they feel their leaders have respect for them and that they value their dignity during a change process. Open communication of leaders to employees to build trust give employees a sense of good intentions for them (Byrne et al., 2005). These supportive behaviours organizations increase the commitment of the employees to be more receptive to change. (House and Mitchell, 1974).

Affective commitment to change is further supported by social exchange theory in which employees see commitment as a two-way process when they perceive the organization to give them training, opportunities to grow, security in the job and return they believe they should give organization, the loyalty and commitment it needs from its employees (Robinson et al., 1994). Therefore, our first hypothesis to be tested is

\section{Hypotheses 1: There exists a positive relationship between ILC and AC}

\subsection{Relationship between ICL and Trust Culture}

Research conducted by (e.g. Dietz and Den Hartog, 2006; Lewicki et al., 2006; Rousseau et al., 1998; Schoorman et al., 2007) showed that trust consists of multiple dimensions and it has multiple facets even: the affective, trust propensity, behavioural element and cognitive elements, perceived characteristics of the trustee, and the position that trustee and trustor hold in the organization. If perceived promises are not fulfilled in the organization, then the employees of that organization seek to behave negatively (Robinson, 1996; Robinson and Rousseau, 1994). (Neves and Caetano (2009) revealed that how the trust in their leader's competencies led to an affective commitment by reducing turnover and increasing overall organizational performance. In an organizational change to accept and be willing to take risks of the change, there are four believes related to trust, the belief that other parties will prove themselves confidential and trustworthy, be honest with what they say and open in their communications, belief that leaders they trust do have such capabilities to process change, and that they are truly sincere with about others best interests (Algahtani, 2014). According to one study trust in management is often characterized as social bond with other parties, a type of social bond in which people exchange their thoughts, receive positive treatments from each other, and create a sense of understanding with each other which improves commitment in the employees (Tyler and Degoey 1996). Grint says that those who possess strong leadership skills can prove himself a good role model because 
his achievements get the trust of the people (Grint, 2007). Leaders are the ones who are responsible for the proper execution of the goals. Effective leaders set optimistic and specific goals and they make effective strategies to achieve those goals. Atkinson in his study said that if there are no good leaders, motivation in employees can't be enhanced and no clear direction can be given to the organization to adopt the change (Atkinson, 2015). Hoverer, a recent take on leadership is to view it from the follower side that comes up with the understanding that leadership is socially constructed, and effective leadership is basically what perceiver thinks. (Meindl, 1995; Van Quaquabeke et al, 2011). Therefore, our second hypothesis to be tested is

\section{Hypotheses 2: There is a positive relationship between ICL and Trust culture}

\subsection{The Mediating Role of Organizational Trust Culture}

Trust has been identified as the factor which shows the willingness to depend on others based on the previous experience about someone being a trustworthy person (Sitkin and Roth, 1993; Mishra, 1996; Mayer et al., 2007). As per this understanding of the trust, it can be defined as an attitude exhibited by employees for the organization and how it leads its employees (Korsgaard et al., 2002). Scholars have defined trust to be an essential part of implementing change (Armenakis et al., 1993). If the subordinates have trust in the abilities of the leader, their performance can show a boost up and their commitment increases (Lee et al, 2010). People follow a person whom they trust that he will show them the right path but not a leader who just posturizes the things but not put his words into actions (Stacey, Paul and Alice, 2011). Trust helps builds commitment in the employees which reduces the resistance to accept change and helps modify the preexisting beliefs and values which are potential barriers to accept change.

If employees want to embrace change, they need to trust their leaders and management, believe that they are trustworthy (Huy, 2002). Leaders who believe in keeping their promise are to be trusted since they are considered to be honest (Bass, 1985). In addition, an exceptional leader being good at active management that is to deal with irregularities are mostly perceived as competent, which is a vital dimension of the trust (Mishra, 1997). Moreover, trust in the leaders plays an intervening role between various outcomes and leadership (Podsakoff et al., 1990). Some researchers argue that trust mediates the relationship between leadership and the internal psychological behaviours such as organizational citizenship, satisfaction and motivation (Pillai et al., 1999).

The literature regarding trust has shown its vitality about how valuable it can be to for the acceptance of the change. For instance, a study by (Reinke 2003) has stated the more there is the trust of employees in their leaders the more readiness employees will show to accept the change. Similarly, another study by (Condrey, 1995) has shown a direct relationship between organizational trust and evaluation of new human resource management system and their supervisor role in the change process as the fundamental one. Therefore, our third hypothesis is:

\section{Hypotheses 3: Trust culture will mediate the positive relationship between ICL and AC.}




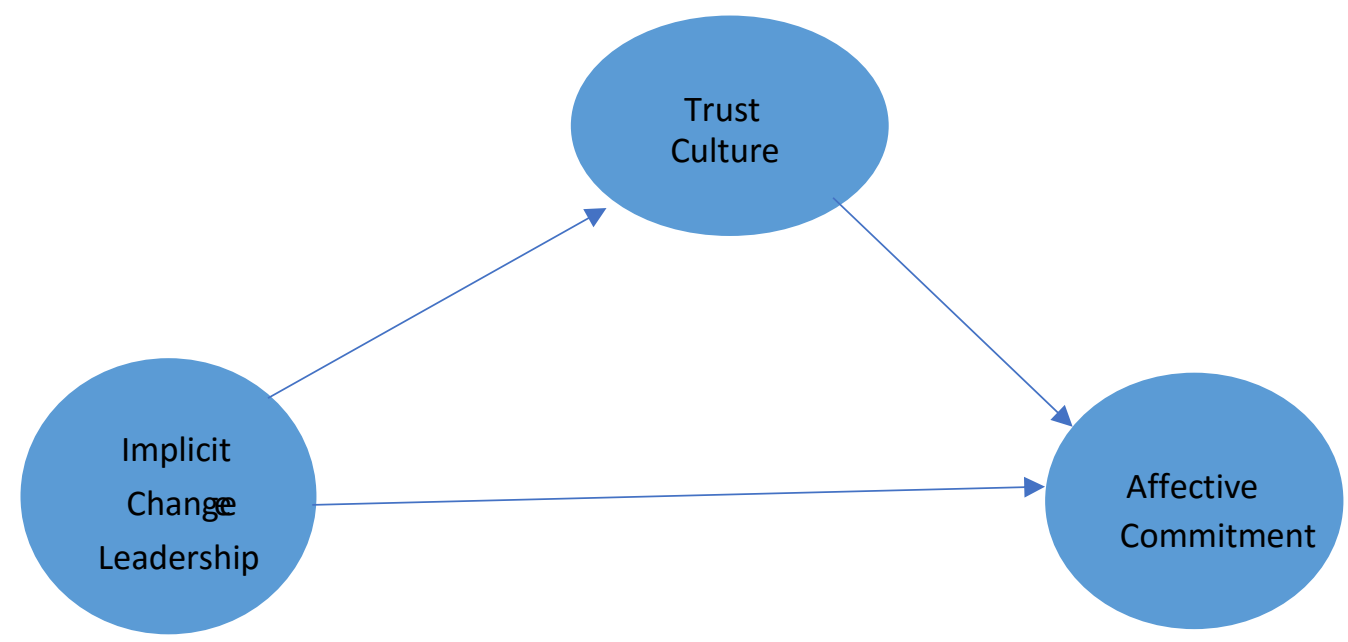

Figure 1: Conceptual Framework

\section{Methodology}

This study was based on convenient sampling. Participants used in this study was lecturers, Assistant professors, Associate Professors, and Professors which were 300 in total. Percentage of male participants were 75.4 and female participants were 24.6. Education of participants ranged from undergraduate to $\mathrm{PhD}$ level. The study was based on university teachers, and the sample has been collected from different universities of Sindh province of Pakistan

\subsection{Measures}

3.1.1 Implicit Change Leadership: ICL tests whether there is a difference between the characteristics of an actual and ideal leader. Measures used in this study were based on 5 competencies of a change leader in which 30 items has been tested. All the items were recorded on a five-point Likert scale with 1 showing "Strongly Disagree" and 5 show "Strongly Agree ".

3.1.2 Strategic and Technical Competencies: six items have been tested which includes if a leader is Open-minded, Proactive, creative, Analytical, possess intelligence, and have long-term thinking.

3.1.3 Character: Three items have been tested which includes if a leader is Credible, Arrogant, and exemplary.

3.1.4 Execution Competencies: Nine items have been tested to see if a leader is Decisive, Lazy, Inspiring, Persuasive, Passive, Micro manages, effective coach or mentor, is organized, and lacks execution.

3.1.5 Social Competencies: Eight items have been tested to see if a leader is a participative, approachable, empathetic, not bossy, supportive, people-oriented, and not distrustful, and effective communicator.

3.1.6 Resilience: Four items have been tested to see if a leader is Optimistic, Adaptable, not sensitive, composed under pressure.

3.1.7 Affective Commitment to Change: Eights dimensions were tested on a five-point Likert scale with 1 showing " Strongly Disagree " and 5 show " Strongly Agree ". Items were "I would be very happy to spend the rest of my career with this institute". "I enjoy discussing my organization with people outside it". "I feel as if this institute's problems are my own". "I think that I could easily become as 
attached to another institute as I am to this one". "

I do not feel like 'part of the family' at my institute". " I do not feel 'emotionally attached' to this institute"." This institute has a much deal of personal meaning for me." I have no strong sense of belonging to my institute".

3.1.8 Organizational Trust: Six items have been tested on a five-point Likert scale with 1 showing "strongly disagree" and 5 show "Strongly Agree". Item was "Our institute members are generally trustworthy". "Our institute members have reciprocal faith in other members' intentions and behaviours". "Our institute members have reciprocal faith in others' ability". "Our institute members have reciprocal faith in others' behaviours to work toward organizational goals". "Our institute members have reciprocal faith in others' decision toward organizational interests than individual interests". "Our institute members have relationships based on reciprocal faith".

\section{Data Analysis and Results}

Compatibility scores for implicit change leadership (ICL) were calculated by getting the difference between actual and ideal. Correlation and mean scores were calculated for each scale. Preceding to the testing of hypothesis, we computed analysis for presuppositions for the bivariate statistic. Durbin Watson test is conducted which is 1.639. Gender, age and education frequency are analyzed from assumptions. At last, regression analysis was used to see the relationship between implicit change leadership (ICL) and affective commitment to change (AC) with mediating role of organizational trust culture (OTC) Cronbach's alpha is computed from assumptions which show data reliability of 0.739.

\subsection{Measurement Model Assessment}

Before testing the hypothesis, we have tested the reliability, discriminant validity and convergent validity of the hypothesis. Further details are present in table 2. It represents that all the Loadings (AC1 0.849) are higher than its level of significance of 0.5 (Barclay et al., 1995; chin, 1998). Average variance of every construct (AC 0525, CH 0.58, EC 0.504, SC 0.522, S\&T0.544, R 0.533, and TC0.502) is exceeding through its nominal threshold of 0.5 (Bagozzi \& Yi, 1988). Results of composite reliability (AC 0.765, TC 0.833 and ICL 0.80086) is also higher than its minimum value recommended (0.70) (Hair et al., 2013). These results are assuring convergent validity and its achievement. So, table 2 suggests the study has significantly attained both the measures validities convergent reliability and scale validity.

Table 2: Assessment of Measurement Model

\begin{tabular}{|l|l|l|l|l|}
\hline Constructs & Items & Loadings & CR & AVE \\
\hline Affective-Commitment & AC1 & 0.849 & 0.765 & 0.525 \\
\hline & AC2 & 0.694 & & \\
\hline & AC3 & 0.61 & & \\
\hline & ICLCHAR1 & 0.594 & & \\
\hline & ICLCHAR2 & 0.898 & & \\
\hline & ICLEC1 & 0.722 & 0.726 & \\
\hline & ICLEC2 & 0.653 & & \\
\hline & ICLEC3 & 0.681 & & \\
\hline & ICLEC4 & 0.759 & & \\
\hline Execution-Competence & ICLEC9 & 0.73 & & \\
\hline & ICLR1 & 0.838 & 0.835 & \\
\hline Social-Competence & ICLR2 & 0.72 & & \\
\hline & ICLR3 & 0.615 & & \\
\hline & ICLSOCIAL2 & 0.691 & 0.845 & 0.522 \\
\hline & ICLSOCIAL3 & 0.708 & & \\
\hline
\end{tabular}




\begin{tabular}{|l|l|l|l|l|}
\hline & ICLSOCIAL5 & 0.684 & & \\
\hline & ICLSOCIAL7 & 0.798 & & \\
\hline & ICLSOCIAL8 & 0.725 & & \\
\hline Strategic-Tech & ICLSTC2 & 0.7 & 0.826 & 0.544 \\
\hline & ICLSTC4 & 0.769 & & \\
\hline & ICLSTC5 & 0.65 & & \\
\hline & ICLSTC6 & 0.82 & & \\
\hline Trust Culture & TC1 & 0.781 & 0.833 & 0.502 \\
\hline & TC2 & 0.793 & & \\
\hline & TC4 & 0.648 & & \\
\hline & TC5 & 0.65 & & \\
\hline Resilience & TC6 & 0.654 & & \\
\hline & ICLR1 & 0.838 & 0.771 & 0.533 \\
\hline & ICLR2 & 0.72 & & \\
\hline & ICLR3 & 0.615 & & \\
\hline
\end{tabular}

Table 3 shows details of the discriminant validity of the current study. Fornell and larcker (1981) that each variable must have a greater square root of AVE (AC 0.725, CH0.762, EC 0.71, R0.73, SC 0.722, S\&T 0.738, TC 0.708) than the correlation and other variables will have discriminant validity. Also, Fornell and Cha (1994) told us the same measures to confirm discriminant validity. So, table 3 reveals that all variables have discriminant validity.

Table 3: Discriminant Validity - Fornell and Larcket Method

\begin{tabular}{|l|l|l|l|l|l|l|l|}
\hline & 1 & 2 & 3 & 4 & 5 & 6 & 7 \\
\hline Affective-Commitment & $\mathbf{0 . 7 2 5}$ & & & & & & \\
\hline Character & 0.337 & $\mathbf{0 . 7 6 2}$ & & & & & \\
\hline Execution-Competencies & 0.623 & 0.449 & $\mathbf{0 . 7 1}$ & & & & \\
\hline Resilience & 0.561 & 0.357 & 0.663 & $\mathbf{0 . 7 3}$ & & & \\
\hline Social-Competencies & 0.596 & 0.425 & 0.699 & 0.638 & $\mathbf{0 . 7 2 2}$ & & \\
\hline Strategic-Tech & 0.504 & 0.424 & 0.613 & 0.516 & 0.56 & $\mathbf{0 . 7 3 8}$ & \\
\hline Trust Culture & 0.656 & 0.319 & 0.569 & 0.556 & 0.529 & 0.454 & $\mathbf{0 . 7 0 8}$ \\
\hline
\end{tabular}

\subsection{Assessment of Structural Model}

With the accomplishment of significant reliability and validity for the research model, the assessment with regard to the structural model was obtained. T-Values (implicit change leadership and affective commitment $=8.973$ and implicit change leadership and trust culture=16.051) got through the bootstrapping procedure with 300 samples. Table 4 depicts the results of hypotheses. Table 4 shows the positive relationship between implicit change leadership and affective commitment $(\beta=0.427, p<0.01)$ and standard error between implicit change leadership and affective commitment is 0.048 .

According to hypothesis 2 relationship between implicit change leadership and trust culture also get empirical acknowledgement by the results $(\beta=0.613, \mathrm{p}<0.01)$ and standard error between implicit change leadership and trust culture is 0.038 . 
Table 4: Assessment of Structure Model

\begin{tabular}{|l|l|l|l|l|l|}
\hline Hypothesis & Relationships & Beta & SE & t-Value & Decision \\
\hline H1 & Change Leadership -> Affective Commitment & 0.427 & 0.048 & $8.973^{* *}$ & Supported \\
\hline H2 & Change Leadership -> Trust Culture & 0.613 & 0.038 & $16.051^{* *}$ & Supported \\
\hline
\end{tabular}

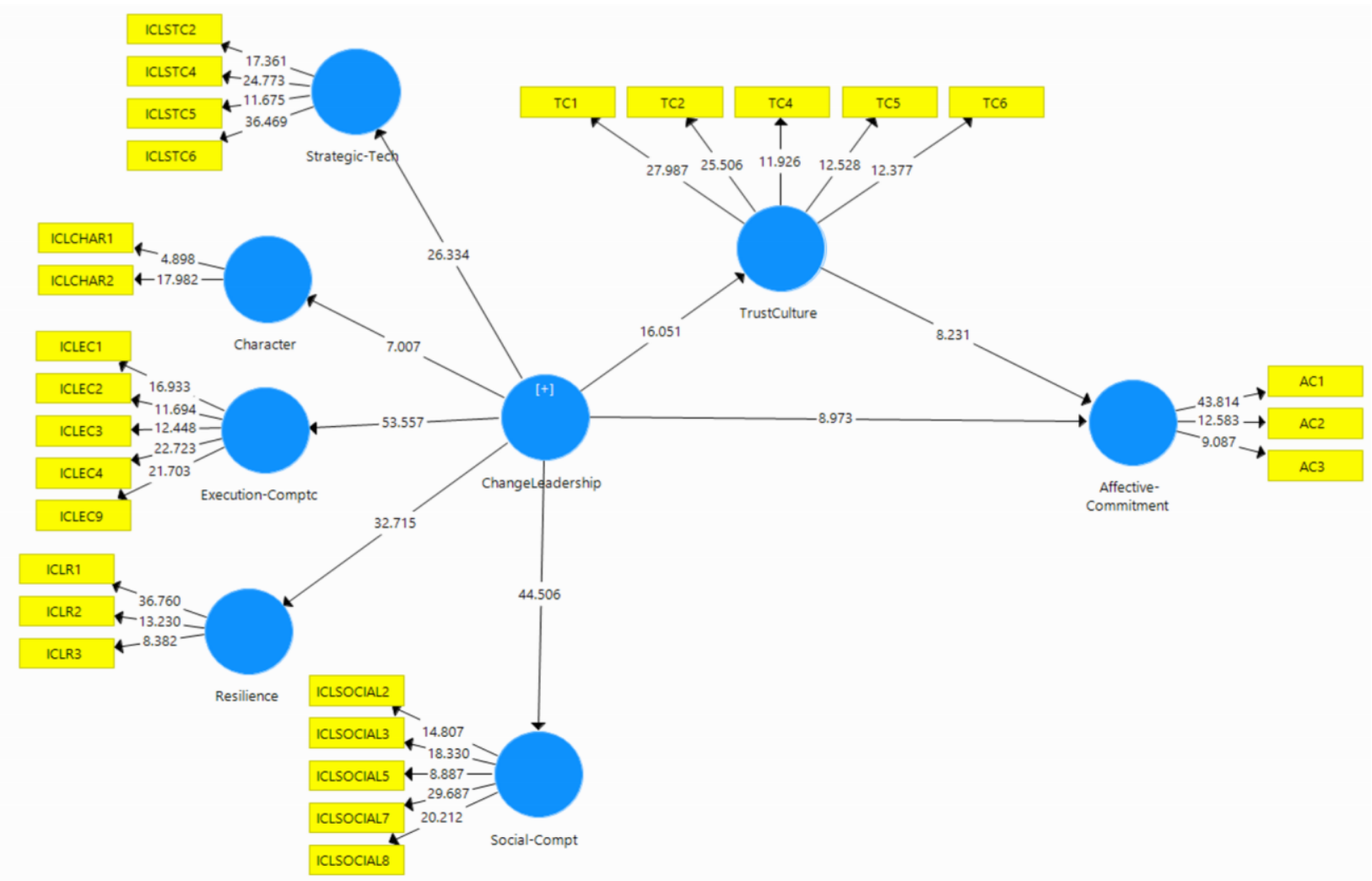

Figure 2: Structure Model

\subsection{Predictive Power of the Model}

In order to determine the predictive power of the model, $\mathrm{R}^{2}$ was analyzed and computed through the PLS algorithm function in Smart PLS 3.0. It was computed for trust Culture which is designed to be the dependent variable in the model. $\mathrm{R}^{2}$ of 0.375 has been determined which is greater than the acceptable value threshold of 0.1 according to the industrial and international research perspective (Falk and Miller, 1992)

Table 5: Assessment of R-Squared

\begin{tabular}{|l|c|}
\hline Construct & $\mathrm{R}^{2}$ \\
\hline Affective-Commitment & 0.545 \\
\hline Trust Culture & 0.375 \\
\hline
\end{tabular}




\subsection{F Squared Assessment}

Effect size is being conducted on the formula $F^{2}=\left(R^{2}\right.$ included $-R^{2}$ excluded $) /\left(1-R^{2}\right.$ included $) . F_{2}$ values are considered to be small when they are 0.02 , considered to be as medium when they are 0.15 , and 0.35 when they are having large effect size. This study found the results that Trust Culture has small effect size $\mathrm{f}^{2}=0.214$ than affective commitment to change. The effect size of the character is also found to be small with $\mathrm{f}=0.45$. However, the effect size of Resilience, Social, Strategic and technical was found to be large. Following table summarizes the results which are discussed.

Table 6: Assessment of F-Squared

\begin{tabular}{|l|l|l|l|l|l|l|l|}
\hline $\begin{array}{l}\text { Dependent } \\
\text { Variables }\end{array}$ & $\begin{array}{l}\text { Affective- } \\
\text { Commitment }\end{array}$ & Character & Execution & Resilience & Social & $\begin{array}{l}\text { Strategic- } \\
\text { Tech }\end{array}$ & $\begin{array}{l}\text { Trust } \\
\text { Culture }\end{array}$ \\
\hline Change Leadership & 0.251 & 0.45 & 3.46 & 1.685 & 3.098 & 1.556 & 0.601 \\
\hline Trust Culture & 0.214 & $\mathrm{n} / \mathrm{a}$ & $\mathrm{n} / \mathrm{a}$ & $\mathrm{n} / \mathrm{a}$ & $\mathrm{n} / \mathrm{a}$ & $\mathrm{n} / \mathrm{a}$ & $\mathrm{n} / \mathrm{a}$ \\
\hline
\end{tabular}

\subsection{Q-Squared Assessment}

To determine the predictive relevance of the dependent variable, the blindfold approach for crossvalidated redundancy of $\mathrm{Q}^{2}$ was computed. The below table presents the blindfold approach results, through which $\mathrm{Q}^{2}$ values for the constructs are found to be greater than zero which suggest that the model do have predictive relevance

Table 7: Assessment of Q-Square

\begin{tabular}{|c|c|c|c|}
\hline & SSO & SSE & $\mathrm{Q}^{2}=(1-\mathrm{SSE} / \mathrm{SSO})$ \\
\hline Affective-Commitment & 900 & 662.799 & 0.264 \\
\hline Trust Culture & $1,500.00$ & $1,238.40$ & 0.174 \\
\hline
\end{tabular}

\subsection{Mediation Analysis}

Regarding hypothesis 3, the mediation effect of trust culture on change leadership and affective commitment to change, the recommendation from preacher and Hayes $(2004$; 2008) has been considered. The Bootstrapping method has been carried out to examine the indirect effects of mediation. Findings have been found positive in which $\beta=0.242, \mathrm{p}<0.01$ ) and with a t-value of 7.715. Moreover, as per Preacher and Hayes research indicated there exists the indirect effect of 0.183 with 97.5 per cent Boot must not straddle a zero and hence suggests a mediating effect.

Table 8: Indirect Effect

\begin{tabular}{|l|l|l|l|l|l|l|}
\hline Hypo: & Relationship & Beta & SE & t-value & $2.50 \%$ & $97.50 \%$ \\
\hline H3 & $\begin{array}{l}\text { Change Leadership -> } \\
\text { Affective-Commitment }\end{array}$ & 0.242 & 0.031 & 7.715 & 0.183 & 0.305 \\
\hline
\end{tabular}

\section{Discussion}

Results support our hypothesis that implicit change leadership do have a positive direct relationship with affective commitment to change and that change leadership schemas positively affects commitment to 
change. Moreover, our second hypothesis has also been supported showing that implicit change leadership schemas also have a positive relationship with organizational trust culture. Our third hypothesis which was to show the mediating effect of trust culture on change leadership and affective commitment to change has also been supported by using the bootstrapping method, and with the t-value of 7.715 and $p$-value of less than 0.01 and with the beta of 0.242 the mediation effect does exist. These results add to the literature and show how important it is for leaders to develop a positive mindset and image in the eyes of employees and subordinates to readily accept change and to show more loyalty and commitment in terms of organizational trust and change.

Results also indicated that the constructs have also passed reliability test with all the constructs of implicit change leadership having more loading than the normal significant level. Of 0.05 . So, it has been shown that the study has convergent reliability which shows that the constructs are in fact related. Furthermore, a discriminant validity test was also conducted, and all the variables proved discriminant validity as shown in table 3 which suggests that those items which are not related are actually not overlapping and are unrelated.

Structural equation modelling and the bootstrapping method was used to prove the hypothesis and infer the decision in which all the decisions were supported. The mediating effect of trust culture was shown and the relationship between implicit change leadership and trust culture was supported with a standard error of 0.038 . The proportion of variance for the dependent variable was found R2 was found more than the acceptable threshold level for the dependent variable. Affective commitment with R2 0.545 shows $54.5 \%$ of the variance accounted by the model, which shows a moderate fit with the model, whereas trust culture with R2 0.375 shows $37.5 \%$ variance accounted by the model. The model has greater than 0 Q2 values which show that the model does have predictive validity with affective commitment having slightly more predictive relevance than the trust culture. This measure shows the importance of creating an organizational trust among employees with having change leaders possessing strong influence and desirable attitude to get the subordinates to accept the change by showing the positive relationships between trust culture and change leadership.

\section{Implications and Conclusion \\ 6.1 Implications}

It has been revealed in the research that how important it is for the leaders to develop a positive attitude in the minds of employees and build a culture in which employees trust in the practices of organization and feel committed to it. It is, therefore, necessary for change leaders to develop such skills and polish their competencies so that in the time when they truly want their organizational members to be adept to change they should not face any difficult convincing them, instead they must not be concerned about the resistance they might face from their employees regarding any change that may occur in an organization and rather should have a firm trusting culture.

\section{Conclusion}

This study confirmed that organizational trust plays a key role in accepting change. It shows that change leaders personality traits do have an influence on the commitment of employees in academic institutions and that trust and commitment collectively build leadership schemas which in turn make the employees feel more loyal to their organizations and readily accept the change. The study was limited to academic institutions of Sindh region; however, culture influences may differ in other provinces. Leadership traits may differ based on the specific cultural aspects of that region. So, future studies can consider the cultural perspective of academic institutions of other provinces as well. Furthermore, future studies can also take the effects of different variables as a mediating effect on change leadership and commitment to change. 


\section{References}

Meindl, J. (1995), "The romance of leadership as a follower-centric theory: a social constructionist approach", The Leadership Quarterly, Vol. 6 No. 3, pp. 329-341

Van Quaquabeke, N., van Knippenberg, D. and Brodbeck, F. (2011), "More than meets the eye: the role of subordinates' self-perceptions in leader categorization processes”, Leadership Quarterly, Vol. 22 No. 2, pp. 367382.

Jowett F. Magsaysay, Ma. Regina M. Hechanova, (2017) "Building an implicit change leadership theory", Leadership \& Organization Development Journal, Vol. 38 Issue: 6, pp.834-848.

Epitropaki, O. and Martin, R. (2005), "From ideal to real: a longitudinal study of the role of implicit leadership theories on leader-member exchanges and employee outcomes", Journal of Applied Psychology, Vol. 90 No. 4, pp. 659-676.

Schyns, B., Kiefer, T., Kerschreiter, R. and Tymon, A. (2011), "Teaching implicit leadership theories to develop leaders and leadership: how and why it can make a difference", Academy of Management Learning \& Education, Vol. 10 No. 3, pp.

397-408.

Popper, M. and Druyan, N. (2001), “Cultural prototypes? Or leaders' behaviors? A study on workers' perceptions of leadership in an electronics industry”, Journal of Managerial Psychology, Vol. 16 No. 7, pp. 549-558.

Offermann, L.R., Kennedy, J.K. and Wirtz, P.W. (1994), "Implicit leadership theories: content, structure, and generalizability", Leadership Quarterly, Vol. 5 No. 1, pp. 43-58.

Saltz, J.L. (2004), "Beyond simple similarity: the relationship of leader-follower personality fit with follower satisfaction with the leader and follower commitment to the organization",

Ma. Regina M. Hechanova, Jaimee Felice Caringal-Go, Jowett F. Magsaysay, (2018) "Implicit change leadership, change management, and affective commitment to change: Comparing academic institutions vs business enterprises", Leadership \& Organization Development Journal, Vol. 39 Issue: 7, pp.914-925.

Armenakis, A. (1993), “Creating readiness for organizational change”, Human Relations, Vol. 46 No. 6 , pp. 681-703.

Fedor, D.B. , Caldwell, S. and Herold, D.M. (2006), "The effects of organizational changes on employee commitment: a multilevel investigation", Personnel Psychology, Vol. 59 No. 1, pp. 1-29.

Herscovitch, L. and Meyer, J.P. (2002), "Commitment to organizational change: extension of a threecomponent model”, Journal of Applied Psychology, Vol. 87 No. 3, pp. 474-487

Cunningham, G. (2006), "The relationships among commitment to change, coping with change, and turnover intentions", European Journal of Work and Organizational Psychology.

Michaelis, B., Stegmaier, R. and Sonntag, K. (2010), "Shedding light on followers' innovation implementation behavior: the role of transformational leadership, commitment to change, and climate for initiative", Journal of Managerial Psychology, Vol. 25 No. 4, pp. 408-429.

Adil, M.S. (2014), "Impact of leader's change-promoting behavior on readiness for change: a mediating role of organizational culture", j o u r n a 1 o f m a n a g m e n t s c i e n c e s, Vol. 1 No. 2, pp. 113-150.

Dietz, G. and Den Hartog, D. (2006), “Measuring trust inside organizations”, Personnel Review, Vol. 35 No. 5, pp. 557-588.

Lewicki, R.J., McAllister, D.J. and Bies, R.J. (1998), "Trust and distrust: new relationships and realities", Academy of Management Review,

Rousseau, D.M., Sitkin, S.B., Burt, R.S. and Camerer, C. (1998), "Not so different after all: acrossdiscipline view of trust", The Academy of Management Review, Vol. 23 No. 3, pp.

393-404.

Schoorman, F.D., Mayer, R.C. and Davis, J.H. (2007), "An integrative model of organizational trust: past, present, and future", Academy of Management Review, Vol. 32 No. 2, pp. 344-354.

Robinson, S.L. and Rousseau, D.M. (1994), "Violating the psychological contract, not the exception but the norm", Journal of Organizational Behavior, Vol. 15 No. 3, pp. 245-259. 
Neves, P. and Caetano, A. (2009), “Commitment to change: contributions to trust in the supervisor and work outcomes", Group and Organization Management, Vol. 34 No. 6, pp. 623-644.

Mayer, R.C., Davis, J.H. and Schoorman, F.D. (1995), “An integrative model of organizational trust", The Academy of Management Review, Vol. 20 No. 3, pp. 709-734.

McAllister, D.J. (1995), "Affect-and cognition-based trust as foundations for interpersonal cooperation in organizations", Academy of Management Journal, Vol. 38 No. 1, pp. 24-59.

Rousseau, D.M., Sitkin, S.B., Burt, R.S. and Camerer, C. (1998), "Introduction to special topic forum: not so different after all: a cross-discipline view of trust", The Academy of Management Review, Vol. 23 No. 3, pp. 393-404.

Whitener, E.M., Brodt, S.E., Korsgaard, M.A. and Werner, J.M. (1998), "Managers as initiators of trust: an exchange relationship framework for understanding managerial trustworthy behavior", The Academy of Management Review, Vol. 23 No. 3, pp. 513-530. [Crossref],

Hao, Moo \& Yazdanifard, Assc. Prof. Dr. Rashad. (2015). How Effective Leadership can Facilitate Change in Organizations through Improvement and Innovation. Global Journal of Management and Business Research (A). 15. 1-6.

Abdulla Ahmed Al-Ali, Sanjay Kumar Singh, Moza Al-Nahyan, Amrik Singh Sohal, (2017) "Change management through leadership: the mediating role of organizational culture", International Journal of Organizational Analysis, Vol. 25 Issue: 4, pp.723-739.

Ann-Louise Holten, Sten Olof Brenner, (2015) "Leadership style and the process of organizational change", Leadership \& Organization Development Journal, Vol. 36 Issue: 1, pp.2-16,

Gilley, Ann \& Gilley, Jerry \& Mcmillan, Heather. (2009). Organizational change: Motivation, communication, and leadership effectiveness. Performance Improvement Quarterly. 21. 75 - 94.

10.1002/piq.20039.

Wen Juan Cai, Mark Loon, Peter Hoi Kin Wong, (2018) "Leadership, trust in management and acceptance of change in Hong Kong's Civil Service Bureau", Journal of Organizational Change Management, Vol. 31 Issue: 5, pp.1054-1070,

Dr Björn Michaelis, Ralf Stegmaier \& Karlheinz Sonntag (2009) Affective Commitment to Change and Innovation Implementation Behavior: The Role of Charismatic Leadership and Employees' Trust in Top Management, Journal of Change Management, 9:4, 399-417. 